\title{
Cell Phone Acne: New Acne Clinical Features in the Coronavirus Disease-19 Era
}

\author{
Kristin Stephanie Sembiring*(i), Nelva Karmila Jusuf \\ Department of Dermatology and Venerology, Faculty of Medicine, Universitas Sumatera Utara, Medan, Indonesia
}

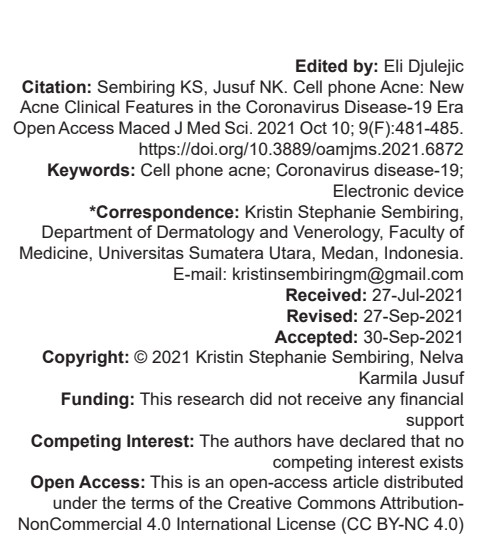

Abstract

Technological developments in telecommunications, especially cell phone, enable us to keep communicate without meeting each other. Especially during the latest coronavirus outbreak, when people need to keep up social distance. Meanwhile, electronic devices such as smartphone, tablets, laptops, and light-emitting diode screens are the sources of visible lights that can emit high levels of short-wavelength visible light (blue region in the light spectrum). Prolonged exposure to high-energy blue light, heat dissipation from cell phone, friction, trapped sweat and oil, accumulation of dust, and increased bacterial growth can cause cell phone acne. Management of cell phone acne from prevention to combination therapy based on the results of the evaluation of the severity of acne is needed.

\section{Introduction}

Rapid telecommunication technology advances have resulted in an exponential growth in the use of electronic devices, such as smart cellular phones (cell phones) and tablets [1]. Increasing use of electronic devices at home, work, and school can affect several dermatological conditions [2], [3]. The latest coronavirus disease (COVID-19) outbreak has spread since 2019. Policy responses controlling the outbreak are lockdown restriction in several countries and recommendations to always keep up social distance. This then triggers an increase in the use of electronic devices, especially mobile phones. Mobile phones are the easiest tool to use to stay connected [4].

Smartphone, tablets, laptops, and lightemitting diode (LED) screens are the sources of visible lights that can emit high levels of short-wavelength visible light (blue region in the light spectrum) [1]. Blue lights are visible light emitted with a wavelength of $400-500 \mathrm{~nm}$. Prolonged exposure to high-energy blue light is said to cause skin problems [2], [5]. The effect of visible light exposure from smartphone devices in a study by Taheri et al. showed an increase in the proliferation of Staphylococcus aureus which may be related to the pathogenesis of acne [1]. The exposure to screens and tablets just before falling asleep was reported by a large majority of subjects in the acne group than in the acne- free group [6], [7].

Acne with a unilateral predominance, first described by Schwartz in 1981, is thought to result from increased thermogenic disturbances from heat sources [8]. Acne with a unilateral predominance is a rare case. In 2017, Sudy reported on this type of unilateral acne after facial palsy [9]. Singh et al. recently in 2020 reported an acne epidemic with unilateral predominance due to cell phone use during the COVID- 19 pandemic. In this study, acne lesions were in the form of new acne eruptions or acne flares with a more severe degree of severity on the side of the face that was more frequently in contact with cell phone [4].

Clinical diagnosis of cell phone acne was same as acne in general. Diagnosis can be obtained through anamnesis and physical examination [10]. The tendency of acne lesions to be more numerous and/ or with a more severe degree of severity on the side of the face that more frequent contact with cell phone, the duration of using the cell phone to the cheek, the habit of using the cell phone against the cheek while charging, and a history of acne need to be considered. Other data regarding cell phone acne are still very limited [4]. 


\section{Cell Phone Acne}

\section{Definition}

Cell phone acne is a condition characterized by the appearance of new acne eruptions or acne flares that are more numerous and/or with a more severe degree of severity on one side of the face due to increased contact between cell phone and skin for a certain period [4].

\section{Epidemiology}

Singh et al. reported cell phone acne cases obtained through teledermatology consultation during the lockdown period (April 1-30, 2020) in India. During this period, 13 patients reported having cell phone acne. The mean age for having acne due to cell phone is $21.71 \pm 8.19$ years. Acne generally experienced by adolescents and young adults (12-25 years old) [10]. The ratio of the incidence of cell phone acne between women and men in this study is 8:5 [4].

The predominance of acne lesions was unilateral. The predominance of acne lesions on the right side of the face is more common $(76.92 \%)$ compared to the left side (23.08\%). About $69.23 \%$ of study subjects reported having experienced acne before. About $30.77 \%$ of subjects reported experiencing acne for the $1^{\text {st }}$ time. The severity of acne on the dominant side (more frequent contact with cell phone) is always more severe [4].

The duration of skin contact on the cheek with a cell phone from the mean $2.47 \pm 2.15 \mathrm{~h}$ before lockdown increased to $3.39 \pm 1.33 \mathrm{~h}$ during lockdown. In addition, 8 out of 13 subjects $(53.33 \%)$ keep his phone pressed against his cheek during charging [4]. Other data regarding acne due to cell phone use, known as "cell phone acne," are still very limited.

\section{Etiopathogenesis}

There are several microorganisms found in the infra infundibulum area. Cutibacterium acnes as the main infundibulum microorganism is a Gram-positive, anaerobic bacteria, increased along with the increase in the amount of triglycerides in sebum which is a nutrient for C. acnes [10], [11], [12]. Nonetheless, it's not only C. acnes which has role in triggering the occurrence of acne vulgaris. Microbiome examination in acne vulgaris lesions by Jusuf et al. shown the results of the culture examination on non-inflammatory lesions found colonization of $S$. aureus (5\%) and another bacteria. The results of aerobic culture examination of inflammatory lesions also found S. aureus colonization (12.5\%) [11].

Prolonged use of smartphones, tablets, laptops, and LED screens is sources of visible light emitting high levels of short-wavelengths visible light (blue light) [1]. Blue light is known as visible light with the highest energy. Exposure to high-energy blue light for a longer time is said to cause skin problems [5]. In line with the theory by Taheri et al., heat dissipation from cell phone, friction, trapped sweat and oil, accumulation of dust, and contamination with microorganisms can cause cell phone acne [4].

To date, study about the relationship between cell phone exposures to increased proliferation of S. aureus has shown. S. aureus growth on electronic devices after long-term visible light exposure was carried out by exposing tablets and smartphones with a distance of 2-3 mm and device's brightness set at $50 \%$. As a control, conventional incandescent light bulb was also exposed to the plate where the bacteria grew. The growth of $S$. aureus, using a spectrophotometer before and after exposure, was higher on smartphones and tablets compared to controls. The increase of bacterial growth is then suspected to be the cause of the increase in inflammatory symptoms in acne [1]. However, research still needs to be done on the relationship between cell phone exposures to other bacteria that play a role in the pathogenesis of acne.

$S$. aureus thought to have the ability to stimulate toll-like receptor 2 (TLR-2) [13]. The role of TLR-2 is through component recognition $S$. aureus which is then expressed in monocytes. Staphylococcus strain can produce toxins such as Staphylococcal exotoxins known as Staphylococcal enterotoxin B (SEB) and alpha toxin. Alpha toxin and SEB can stimulate monocytes [14]. Then, it will stimulate T-helper cell (Th) to produce pro-inflammatory cytokines such as IL-1ß, IL-8, and IL-12. These cytokines will later play a role in the pathogenesis of chronic inflammatory skin diseases such as acne vulgaris and psoriasis [13], [14].

The pathogenesis of acne vulgaris, in general, is multifaceted. There are four pathogenesis factors that have been identified, namely, hyperproliferation of epidermal follicles, sebum production, C. acnes, and inflammatory and immune responses [10], [12]. Acne vulgaris known today is a complex and multifactorial inflammatory disorder. Each of these processes is interrelated and under the influence of hormones and immunity [10].

Epidermal follicular hyperproliferation has a role in producing microcomedones. Excessive number of cells will result in blockage of the follicular ostium. This blockage can lead to an accumulation of keratin, sebum, and bacteria in the follicle. This buildup will cause dilatation of the upper hair follicles resulting in microcomedones, which are precursors of comedones and inflammatory lesions [10], [12], [13].

Excessive sebum production from the sebaceous glands is a pathogenesis that also plays a role in acne [10], [12]. Human sebum contains several components such as squalene, cholesterol, cholesterol esters, wax esters, and triglycerides when 
leaving the sebaceous glands. During the passage of sebum through the hair canal, enzymes from bacteria hydrolyze a number of triglycerides [15]. Sebum components form of triglycerides will be broken down by $C$. acnes (normal flora in pilosebaceous units) into free fatty acids. These free fatty acids will later cause bacterial blockage and colonization of bacteria $C$. acnes, promote inflammation, and possibly lead to comedone formation. Lipoperoxidase also produces pro-inflammatory cytokines and activates the proliferator-activating receptor pathway, causing an increase in sebum [10], [15].

It was initially thought that inflammation was followed by comedone formation, but there is evidence to suggest that dermal inflammation is actually preceded by comedone formation. Biopsy taken from acne-prone skin but free of comedones, showed increased dermal inflammation compared to normal skin. Biopsy of newly formed comedones reveals greater inflammation. This suggests that inflammation is actually preceded by the formation of comedones [15].

\section{Diagnosis}

Clinical diagnosis of cell phone acne can be obtained through anamnesis and physical examination as well as supporting examinations such as acne in general [16]. Cell phone acne risk factors can be identified through history taking. Cell phone acne risk factors are infrequent cleaning of the cell phone screen, increased duration of contact with one side of the face with the cell phone, the habit of using a cell phone that contacts the cheek during charging, and a previous history of acne [4].

On physical examination, flare acne lesions were found with a more severe degree of severity on the side of the face that was more frequently in contact with cell phone while talking. The clinical lesions of cell phone acne are generally the same as acne vulgaris [4]. Acne lesions consist of non-inflammatory lesions, such as open comedones and closed comedones, and inflammatory lesions such as papules, pustules, and nodules with varying degrees of inflammation and depth [10].

Assessment of the severity of cell phone acne refers to the assessment of the severity of acne vulgaris [4]. Assessment is determined through a grading system based on the observation of the dominant lesion, evaluation of the presence of inflammatory lesions, and the area of skin involved. The results of this scoring system will result in the division of acne vulgaris into certain degrees of severity. There is no universally agreed scoring system to date [17], [18].

\section{Prevention}

Cell phone should be cleaned regularly to prevent emergence of new acne lesion or acne flare on cell phone acne. Each phone manufacturer's recommendations vary, Apple recommends cleaning with a soft, slightly damp, lint-free cloth [19]. Disinfection can be done using $70 \%$ isopropyl alcohol wipes or bleach-free disinfectant wipes. Bleach and disinfectants containing vinegar should be avoided. Contact with the skin can be reduced by turning the side of the phone. Furthermore, the use of hands-free and Bluetooth- enabled devices may be a better option. Call time should be reduced to prevent the phone from heating up and the use of the phone while charging should be avoided [4].

Prevention of acne generally depends on successful management of the risk factors involved in the development of acne, including the underlying systemic disease and lifestyle factors. If several systemic diseases associated with acne vulgaris are managed properly, acne can be prevented. Various lifestyle factors, such as dietary habits, obesity, and smoking, can influence the development of acne [12].

Management of lifestyle factors by eliminating stress properly, not solving acne lesions, avoiding the use of acnegenic drugs, oils, and heavy cosmetics, having a balanced diet, avoiding a high glycemic index diet, and washing your face regularly with soap and water can prevent this from happening acne. However, lifestyle intervention effect on acne is still a debated issue. Existing epidemiological studies still show contradictory results, so a good study design is needed to be able to produce evidence-based research results [20], [21], [22]

\section{Management of Cell Phone Acne}

Cell phone acne management is the same as the management of acne vulgaris in general [4]. Combination therapy is the most rational approach since acne is a multifactorial disease [23]. There are several guidelines for the management of acne vulgaris currently available. Treatment of acne vulgaris begins with evaluating acne based on its severity, which is divided into mild, moderate, and severe [22].

Pharmacological agents are used for the treatment of acne which are topical and systemic therapy. Topical therapy that can be used is topical retinoids (tretinoin, isotretinoin, adapalene, and tazarotene), benzoyl peroxide, and topical antibiotics [10], [22], [23]. Other topical agents that can be used are azelaic acid (used in comedonal and inflammatory acne), salicylic acid (comedolytic agent), lactic acid, dapsone, 
clindamycin, and sulfur. Treatment using other therapeutic modalities should be considered as a treatment strategy until there are high-quality studies to demonstrate their effectiveness [10], [23].

Systemic therapy that can be used is systemic antibiotics. Oral antibiotics that are often used are tetracycline, doxycycline, minocycline, and lymecycline [10], [21], [23]. In addition to tetracycline derivatives, sulfa derivatives such as cotrimoxazole and dapsone can also be used; macrolides such as erythromycin and azithromycin. Hormonal therapy, such as estrogen, anti-androgens; corticosteroids; oral zinc therapy; and oral retinoids such as isotretinoin can also be used to treat acne [10], [21], [23].

Adjuvant (additional) therapy together with the main therapy for acne can accelerate the improvement and/or improve the condition of the skin as treatment progresses. Adjuvant acne therapy begins with asking about skin care routines. Skin care routines consist of the frequency of cleaning the skin and the selection of cleansers and moisturizers used [20]. Choi et al. advised patients with acne to clean the skin a maximum of twice a day with a mild cleanser [24]. A good skin cleanser has a significant effect on the lipid content of the skin. The use of acne medications for dry skin types such as benzoyl peroxide, clindamycin, salicylic acid, and retinoids must be accompanied by the use of non-foaming cleansers containing barrier-repairing and non-comedogenic ingredients [25].

Skin care continues with the selection of the right moisturizer. Oily skin types will prefer moisturizers that contain humectants, contain hyaluronic acid and heparan sulfate analogs [26]. Dry skin types use a moisturizer that contains barrier repair with the right ratio of ceramides, fatty acids, and cholesterol, which is $1: 1: 1$ [25]. Moisturizers are applied before the application of topical acne medications. Moisturizers can minimize irritation in patients with sensitive skin types. Irritation from using topical acne medications peaks at about 2 weeks and then subsides overtime with continued use [22]

The use ofsunscreenshould berecommended in acne patients with post-inflammatory hyperpigmentation to prevent further hyperpigmentation [22]. The oily sensation caused by sebum on the skin of patients with oily skin types causes a tendency to not use sunscreen. This is because most sunscreen products are made of silicone and oil-soluble ingredients, which make the skin feel greasy. For this reason, very oily skin types should use sunscreen instead of moisturizer and some oily skin types should use a lighter lotion or serum type moisturizer [25].

Chemical peeling with $10-50 \%$ glycolic acid or $10-30 \%$ salicylic acid can help treat non-inflammatory (comedonal) lesions [10], [21], [23]. Another adjuvant therapy such as cyst aspiration, intralesional steroids, and systemic antibiotics also can be performed for cystic acne [20], [21], [22], [23].

\section{Conclusion}

Rapid telecommunication technology advances along with the increasing use of electronic devices can affect several dermatological conditions. The latest coronavirus (COVID-19) outbreak is one of the triggers for the increase in the use of cell phone with the lockdown restriction. The effect of cell phone exposure to visible light can increase the proliferation of bacteria, possibly related to the pathogenesis of acne. To date, study about the relationship between cell phone exposures to increased proliferation of $S$. aureus has shown. However, research still needs to be done on the relationship between cell phone exposures to other bacteria that play a role in the pathogenesis of acne. Heat dissipation from cell phone, friction, trapped sweat and oil, accumulation of dust, and contamination with microorganisms also related to the pathogenesis of cell phone acne. Data regarding cell phone acne are still very limited. Prevention of cell phone acne is done by eliminating the risk factors involved in the development of acne. Management of cell phone acne is the same as acne in general. Combination therapy with pharmacological agents, skin care, and adjuvant therapy is required to treat acne.

\section{References}

1. Taheri M, Darabyan M, Izadbakhsh E, Nouri F, Haghani M, Mortazavi SA, et al. Exposure to visible light emitted from smartphones and tablets increases the proliferation of staphylococcus aureus: Can this be linked to acne? J Biomed Phys Eng. 2017;7(2):163-8.

PMid:28580338

2. Keykhosravi A, Neamatshahi M, Mahmoodi R, Navipour E. Radiation effects of mobile phones and tablets on the skin: A systematic review. Adv Med. 2018;2018:9242718. https://doi. org/10.1155/2018/9242718

PMid:29850642

3. Corazza M, Minghetti S, Bertoldi AM, Martina E, VirgiliA, Borghi A Modern electronic devices: An increasingly common cause of skin disorders in consumers. Dermatitis. 2016;27(3):82- 9. https://doi.org/10.1097/der.0000000000000184

PMid:27172301

4. Singh $M$, Pawar M, Maheswari A, Bothra A, Khunger N 'Cell- phone acne' epidemic during the COVID-19 pandemic. Clin Exp Dermatol. 2020;45(7):891-921. https://doi.org/10.1111/ ced. 14360

PMid:32598514

5. Coats JG, Maktabi B, Abou-Dahech MS, Baki G. Blue light protection, Part I-effects of blue light on the skin. J Cosmet Dermatol. 2020;20(3):714-7. https://doi.org/10.1111/jocd.13837 PMid:33247615

6. Dreno B, Shourick J, Kerob D, Bouloc A, Taïeb C. The role of exposome in acne: Results from an international patient survey. J Eur Acad Dermatol Venereol. 2019;34(5):1057-64. https://doi. org/10.1111/jdv.16119 


\section{PMid:31785166}

7. Yang J, Yang $\mathrm{H}, \mathrm{Xu}, \mathrm{A}, \mathrm{He} \mathrm{L}$. A review of advancement on influencing factors of acne: An emphasis on environment characteristics. Front Public Health. 2020;8:450. https://doi. org/10.3389/fpubh.2020.00450

\section{PMid:33042936}

8. SchwartzWF. Unilateral acne:The case for thermogenicaggravation, and a clue to basic acne therapy. Cutis. 1981;27(5):530-1. PMid:6453700

9. Sudy E. Unilateral acne after facial palsy. An Bras Dermatol. 2018;93(3):441-2. https://doi.org/10.1590/ abd1806-4841.20187437 PMid:29924238

10. Goh C, Cheng C, Agak G, Zanglein AL, Graber EM, Thiboutot DM, et al., editors. Fitzpatricks' Dermatology in General Medicine. $9^{\text {th }}$ ed. New York: McGraw Hill Companies; 2019. p.1391-412.

11. Jusuf NK, Putra IB, Sari L. Differences of microbiomes found in non-inflammatory and inflammatory lesions of acne vulgaris. Clin Cosmet Investig Dermatol. 2020;13:773-80. PMid:33122933

12. Zouboulis CC. Skin glands: Sebaceous, eccrine, and apocrine glands. In: Kang S, Amagai M, Bruckner AL, Enk AH, Margolis DJ, McMichael AJ, et al., editors. Fitzpatricks's Dermatology in General Medicine. $9^{\text {th }}$ ed. New York: McGraw Hill Companies; 2019. p. 70-88.

13. Totte JE, Feltz WT, Bode LG, Belkum A, Zuuren EJ, Pasmans SG. A systematic review and meta-analysis on Staphylococcus aureus carriage in psoriasis, acne and rosacea. Eur J Clin Microbiol Infect Dis. 2016;35(7):1069-77. https://doi. org/10.1007/s10096-016-2647-3 PMid:27151386

14. Niebuhr M, Schorling K, Heratizadeh A, Werfel T. Staphylococcal $\alpha$-toxin induces a functional upregulation of TLR-2 on human peripheral blood monocytes. Exp Dermatol. 2015;24(5):381-3. https://doi.org/10.1111/exd.12674

PMid:25707385

15. Bernadette I. Patogenesis Akne Vulgaris. In: Wasitaatmadja SM, editor. Jakarta: Badan Penerbit Fakultas Kedokteran Universitas Indonesia; 2018. p. 1-8.

16. Kapantow GM. Diagnosis Klinis Akne. In: Wasitaatmadja SM, editor. Jakarta: Badan Penerbit Fakultas Kedokteran Universitas
Indonesia; 2018. p. 9-26.

17. Ramli R, Malik AS, Hani AF, Jamil A. Acne analysis, grading and computational assessment methods: An overview. Skin Res Technol. 2012;18(1):1-14. https:// doi. org/10.1111/j.1600-0846.2011.00542.x PMid:21605170

18. Becker M, Wild T, Zouboulis C. Objective assessment of acne. Clin Dermatol. 2017;35(2):147-55.

PMid:28274351

19. Apple Support. Cleaning Your iPhone; 2020. Available from: https://www.support.apple.com/en-gb/ht207123. [Last accessed on 2021 May 16].

20. Wasitaatmadja SM, Arimuko A, Norawati L, Bernadette I, Legiawati L, editors. Pedoman Tata Laksana Akne di Indonesia. $2^{\text {nd }}$ ed. Jakarta: Centra Communications; 2016. p. 1-16.

21. Tuchayi SM, Makrantonaki E, Ganceviciene R, Dessinioti C Feldman SR, Zouboulis CC. Acne vulgaris. Nat Rev Dis Primers. 2015;1:15029. https://doi.org/10.1038/nrdp.2015.29 PMid:27189872

22. ZaengleinAL.Acnevulgaris. NEng JMed. 2018;379(14):1343-51. PMid:30281982

23. Zaenglein AL, Pathy AL, Schlosser BJ, Alikhan A, Baldwin HE, Berson DS, et al. Guidelines of care for the management of acne vulgaris. J Am Acad Dermatol. 2016;74(5):945-73.e33. PMid:26897386

24. Choi JM, Lew VK, Kimball AB. A single-blinded, randomized, controlled clinical trial evaluating the effect of face washing on acne vulgaris. Pediatr Dermatol. 2006;23(5):421-7. https://doi. org/10.1111/j.1525-1470.2006.00276.x PMid:17014635

25. Baumann L. Cosmeceuticals and skin care in dermatology In: Kang S, Amagai M, Bruckner AL, Enk AH, Margolis DJ, McMichael AJ, et al. Fitzpatrick's Dermatology. $9^{\text {th }}$ ed. United States: McGraw Hill; 2019. p. 3803-19.

26. Zettersten EM, Ghadially R, Feingold KR, Crumrine D, Elias PM. Optimal ratios of topical stratum corneum lipids improve barrier recovery in chronologically aged skin. J Am Acad Dermatol. 1997;37(3):403-8. https://doi.org/10.1016/ s0190-9622(18)30737-0

PMid:9308554 